\title{
Forethought development in children and adolescents
}

\author{
LINDA J. SANDHAM \\ University of Nebraska, Omaha, Nebraska 68182 \\ and \\ ROBERT A. HICKS \\ San Jose State University, San Jose, California 95192
}

\begin{abstract}
Using a large set of items that were generated to reflect the dimensions of forethought suggested by the existing literature, a 41-item forethought scale (FS) was developed. This scale measures three factors: remote-future time comprehension, real-time consequences, and important future events. To measure the trends in the development of these factors of forethought and to test certain assumptions concerning the timing of the development of this trait, the FS items were administered to 400 boys and girls (age range $=3$ to 18 years). Using scores for each of the three factors and age as variables, an analysis of variance showed that only the main effect for age and the Age by FS Factors interaction were significant. Factor means demonstrated that for two FS dimensions, real-time consequences and important future events, development was virtually complete by age 10 years. However, for the remote-future time comprehension factor, development was not complete until late adolescence.
\end{abstract}

The rationale for this research was derived primarily from Arieti's (1957) descriptive account of the ontogeny of forethought. He defined forethought as the capacity to foresee or predict future events, even when there are no external stimuli that are directly or indirectly related to the events. An evaluation of Arieti's words suggests that forethought is a multidimensional construct that develops with age.

With regard to the concept of multidimensionality, Arieti (1957) suggested that forethought might be composed of as many as five dimensions, which include (1) the understanding of real-time consequences, (2) the anticipation of important future events, (3) the comprehension of death, (4) the understanding of cyclic variations in the natural environment, and (5) the sense of time.

With regard to the development of forethought with age, there is disagreement in the literature as to the age at which the development of forethought is relatively complete. Depending on the construct measured, the age has been fixed between 8 years (Ames, 1946) and 14 years (Swain, 1975).

Studies (Piaget, 1955, 1969b, 1972; Werner \& Kaplan, 1963) on the development of the understanding of causality, reflecting the understanding of real-time consequences, have shown that the child's causal reasoning is like that of an adult by age 7 or 8 years.

Other studies (Ames, 1946; Anthony, 1972; Childers \& Wimmer, 1971; Nagy, 1948; Swain, 1975; Zweig,

The forethought scale and a copy of the rotated factor matrix are available on request.
1976) that address the anticipation of important future events (e.g., death) have suggested that children show an adult understanding of these constructs between the ages of 7 and 14 years.

In addition, studies (Friedman, 1976, 1977) on the understanding of cyclic variations in the natural environment have shown that a complete understanding of cyclic variations is not yet complete at age 10 years, although it is much more developed at this age than at younger ages.

Finally, research has measured the development of the comprehension of logical and conventional time in children. Ames (1946) set the understanding of the meaning of conventional time (including proximate future time) at 8 years of age, and Piaget (1969a) suggested that the child is able to organize systems of measuring time and to develop a logical understanding of time from ages 7 to 11 years.

The range of ages found in the literature is probably more indicative of the need to define forethought as a multidimensional construct whose component constructs develop differentially by age than it is evidence of conflict in the literature. This research was conducted to test both Arieti's (1957) claim that forethought is a multidimensional construct and the previous research findings.

\section{METHOD}

\section{Subjects}

Subjects were 400 children who ranged in age from 3 to 18 years. Three hundred children, 3-14 years of age, were from public and private schools in the San Francisco Bay area, and 
100 children, 15-18 years of age, were from public schools in Omaha, Nebraska. Age groups were arbitrarily divided into eight groups of 2 years each.

\section{Procedure}

A 66-item questionnaire was written to reflect the five dimensions of forethought development and administered to the sample of 300 children, that is, 25 males and 25 females from each of the six age groups (Sandham, 1980). The rotated factor matrix that was computed from the children's responses to this set of items revealed three factors that were sufficiently determined to name. All items from the original pool of items that did not load on any of the three factors were discarded. The remaining 41 items, constituting the forethought scale (FS), were rescored so that three separate factor scores were derived for each child. Nineteen items measured Factor 1 (remote future time comprehension), 14 items measured Factor 2 (realtime consequences), and 8 items measured Factor 3 (important future events).

These items were then administered to the sample of 100 adolescents, that is, 25 males and 25 females from the two remaining age groups.

\section{RESULTS}

The means on each of the three factors for each age group are shown in Figure 1. (Sex was dropped as a variable because it did not prove to be significant.)

Data were converted to standard scores and a threeway (age, sex, and FS factors) analysis of variance was computed. Only the main effect of age $(F=230.05$, $\mathrm{p}<.001)$ and the Age by FS Factor interaction $(\mathrm{F}=13.58, \mathrm{p}<.001)$ were significant.

\section{DISCUSSION}

Results of this study support both Arieti's (1957) claim that forethought is a multidimensional construct and previous research (Ames, 1946; Anthony, 1972; Childers \& Wimmer, 1971; Friedman, 1976, 1977; Nagy, 1948; Piaget, 1955, 1969a, 1969b, 1972; Swain, 1975; Werner \& Kaplan, 1963; Zweig,

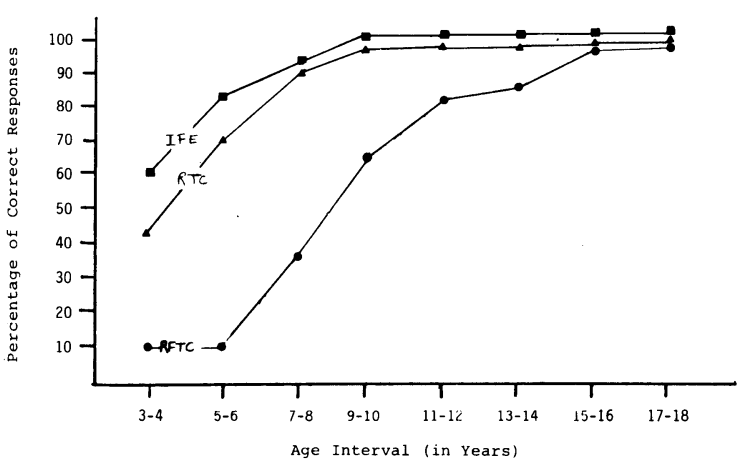

Figure 1. The percentage of correct responses on each of the three FS factors for each of the eight age intervals. (Boys and girls were combined in each age group because sex was not a significant variable in the ANOVA.)
1976) that showed that the dimensions of forethought develop differentially by age (see Figure 1).

Furthermore, these results generally support previous research (Ames, 1946; Anthony, 1972; Childers \& Wimmer, 1971; Nagy 1948; Piaget, 1955, 1969a, 1972; Swain, 1975; Werner \& Kaplan, 1963; Zweig, 1976) that demonstrated that the understanding of real-time consequences and the anticipation of important future events are accomplished by the age of 7 to 14 years. Our data indicate that these two factors are virtually complete by age 10 years.

However, unlike earlier research, this study also measured the child's development of remote-future time comprehension. Mean scores for this factor (see Figure 1) demonstrated that the development of remote-future time concepts is not completed until late adolescence. These findings do not conflict with those of Ames (1946) and Piaget (1969a), since their research was not designed to measure the developmental trends of remote-future time concepts. Rather, they suggested that the onset of the ability to foresee the remote future in children and the completion of this ability requires a greater level of maturity than is needed to understand the other factors involved in forethought development.

Finally, our data provide some guidance to the design of future research because we have demonstrated that a comprehensive study of the development of forethought should use an empirically derived, multidimensional response measure and focus on a thorough definition of the age parameters of each of these dimensions.

\section{REFERENCES}

Ames, L. B. The development of the sense of time in the young child. Journal of Genetic Psychology, 1946, 68, 97-125.

Anthony, S. The discovery of death in childhood and after. New York: Basic Books, 1972.

ArIETI, S. The process of expectation and anticipation: Their genetic development, neural basis and role in psychopathology. Journal of Nervous and Mental Disease, 1957, 196, 471-481.

Childers, P., \& Wimmer, M. The concept of death in early childhood. Child Development, 1971, 42, 1299-1301.

Friedman, W. The development of children's understanding of temporal cycles. Unpublished doctoral dissertation, University of Rochester, 1976.

Friedman, W. The development of children's understanding of cyclic aspects of time. Child Development, 1977, 48, 15931599.

NAGY, M. H. The child's theories concerning death. Journal of Genetic Psychology, 1948, 73, 3-27.

Pinart, J. The language and thought of the child. New York: Meridian, 1955.

Pinaet, J. The child's conception of time. New York: Basic Books, 1969. (a)

Pinaet, J. Judgment and reasoning in the child. Totowa, N.J: Littlefield, Adams, 1969. (b)

Piaget, J. The child's conception of physical causality. Totowa, N.J: Littlefield, Adams, 1972.

Sandham, L. J. Age dependent forethought in children. Unpublished master's thesis, San Jose State University, 1980.

Swain, H. L. The concept of death in children. Unpublished doctoral dissertation, Marquette University, 1975.

Werner, H., \& Kaplan, B. Symbol formation. New York: Wiley, 1963.

ZwEIG, A. R. Children's attitudes towards death. Unpublished doctoral dissertation, Northwestern University, 1976.

(Received for publication July 9, 1982.) 